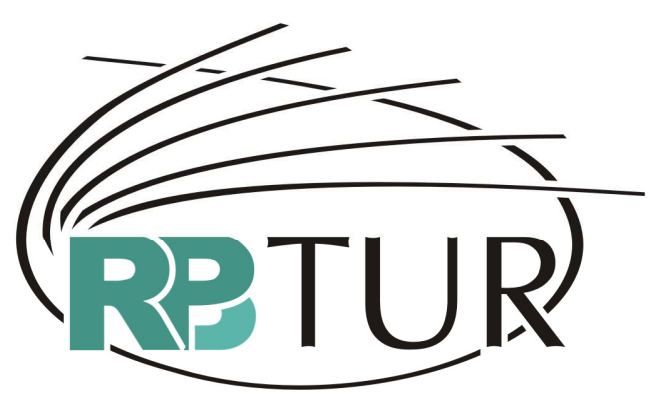

REVISTA BRASILEIRA DE PESQUISA EM TURISMO

\title{
PATRIMÔNIO CULTURAL E TURISMO: UM ESTUDO DE CASO SOBRE A RELAÇÃO ENTRE A POPULAÇÃO PARNAIBANA E $O$ COMPLEXO PORTO DAS BARCAS
}

\author{
HERITAGE AND TOURISM: A CASE STUDY ON THE \\ RELATIONSHIP AMONG PARNAÍBA/PI DWELLERS AND \\ "PORTO DAS BARCAS" COMPLEX
}

\section{PATRIMONIO CULTURAL Y TURISMO: UN ESTUDIO DE CASO SOBRE LA RELACIÓN ENTRE LA POBLACIÓN DE PARNAIBA/PI Y EL COMPLEJO "PORTO DAS BARCAS"}

\author{
Andre Riani Costa Perinotto ${ }^{1}$ \\ Anna Karolina Pereira dos Santos ${ }^{2}$
}

Resumo: A atividade turística assume um papel muito importante dentro da sociedade. Além de proporcionar desenvolvimento através da geração de emprego e renda pode se tornar um grande incentivador da cultura e, por conseguinte, a valorização do patrimônio histórico-cultural de um povo. Este trabalho tem como objetivo avaliar a sensibilização e a valorização histórico-cultural que a população parnaibana atribuiu ao Porto das Barcas, bem como caracterizar o nível de conhecimento sobre sua história. Como forma de alcançar esses objetivos, usou-se um conjunto de procedimentos tais como entrevistas informais, utilizadas para ampliar o conhecimento sobre o assunto, e questionários com perguntas abertas e fechadas, que visam uma avaliação da população local, do poder público e privado, acerca do Porto das Barcas. Fez-se uso da pesquisa bibliográfica, observação e estudo de caso, pesquisa quantitativa e qualitativa, assim como a análise SWOT para poder avaliar o objeto de estudo. Após as análises foi observado que a população de

${ }^{1}$ Bacharel em Turismo (UNIMEP); Especialista em Docência em Ensino Superior para Turismo e Hotelaria (SENAC/SP); Mestre em Geografia (UNESP/Rio Claro/SP) e Doutorando em Comunicação (UNISINOS). Professor Assistente 2 da Universidade Federal do Piauí - Curso de Bacharelado em Turismo - CMRV/Parnaíba-PI. Email: perinotto@ufpi.edu.br

2 Graduada em Turismo pela UFPI (Universidade Federal do Piauí). Email: kali_karol@hotmail.com 
Parnaíba/PI ainda não despertou para a importância de seu patrimônio. Sendo assim, têm-se como propostas a implantação de uma educação patrimonial além de um museu fotográfico que possibilite ao parnaibano interagir com o Porto.

Palavras chave: Turismo. Turismo Cultural. Patrimônio histórico-cultural. Complexo Porto das Barcas.

Abstract: Tourism plays a very important role within society. In addition to providing development by generating jobs and income it is a potential great supporter of culture leading to increase value of cultural heritage. This article aims to evaluate Paraiba's dwellers perception on "Porto das Barcas" (Boates Port) as heritage as well as to assess their knowledge about the history of the place. To achieve these goals, informal interviews were conducted, to better know the investigated issue and questionnaires with open and closed questions to assess the perception of dwellers, public servants and privet sector. Bibliographic research, observation, case study, quantitative and qualitative research as well as SWOT analysis were also part of the investigation. As a result researchers concluded that local dwellers do not still perceive the importance of Porto das Barcas heritage, so a heritage education program is proposed as well as a photographic museum to favor interaction between Paraiban citizens and their port.

Keywords: Tourism. Cultural Tourism. Historic and cultural heritage. Porto das Barcas Complex.

Resumen: La actividad turística presenta un papel muy importante dentro de la sociedad. Además de proporcionar el desarrollo mediante la generación de empleo y renta puede llegar a ser un defensor de la cultura y, por lo tanto, la apreciación del patrimonio cultural de un pueblo. Este estudio tiene como objetivo evaluar el conocimiento y reconocimiento de la población parnaibana histórico-cultural asignado al "porto das barcas", como también la caracterización del nivel de conocimiento sobre su historia, por lo que se comprende la razón del desamparo, tal fenómeno cada vez más común en sitio ya mencionado. Como una manera de lograr estos objetivos del estudio, hemos utilizado un conjunto de procedimientos para alcanzar el objetivo de la presente investigación, como por ejemplo, las entrevistas informales, que se utilizan para aumentar el conocimiento sobre el tema, y los cuestionarios con preguntas abiertas y cerradas, que objetivan a una evaluación de la población local de los poderes del gobierno y privado, sobre el "Porto das Barcas". Hemos utilizado la investigación bibliográfica, la observación y estudio de caso, la investigación cualitativa y cuantitativa, así como el análisis SWOT para evaluar el objeto del trabajo. Por tanto, tras el análisis se observó que la población de Parnaíba/PI aún no ha despertado de la importancia de su patrimonio. Esta observación se caracteriza por el mismo desinterés en participar de proyectos para revitalizar el centro histórico, de esta manera tenemos como propuestas la implantación de una educación patrimonial como también un museo fotográfico que permitan a los "parnaibanos" interactuar con el puerto.

Palabras clave: Turismo. Turismo Cultural. Patrimonio histórico y cultural. Complejo Porto das Barcas. 
ISSN: $1982-6125$

\section{Introdução}

O turismo é uma atividade que cresce cada vez mais, admitindo vários conceitos e segmentações. Vem ganhando espaço principalmente no Brasil, um país que possui muitas riquezas ainda a serem exploradas de forma sustentável. No entanto, na intenção de caracterizar melhor este trabalho será apresentado um segmento, o turismo cultural, que, para muitos, é tão amplo que pode ser considerado como toda forma de turismo.

O turismo cultural tem como produto o patrimônio, que entre outras definições, assume, originalmente, o sentido de herança familiar, principalmente se relacionados aos bens materiais. No entanto, na finalidade de se adequar a este trabalho, coloca-se o patrimônio cultural como aquilo que pertence a um povo, que foi deixado através de uma herança cultural, passando de geração em geração, transmitindo consigo um legado de representações que, por si só, diferenciam as civilizações, umas das outras.

Pensar o espaço turístico a partir de suas formas arquitetônicas antigas significa um esforço de interpretação do mundo vivido pelos grupos sociais que antecederam a vida moderna (urbana pós-industrial) e que, sem sombra de dúvida, desperta o interesse e a curiosidade dos turistas, contudo tem-se a necessidade de se pensar nos patrimônios históricos além da estrutura, pois estes são um resultado de um processo histórico em que o mundo vivido sofreu interferências de tempo e culturais muito específicas, de acordo com a gama de traços culturais que cada grupo imprimiu em seus espaços de vida social.

Escrever sobre um patrimônio histórico não é dizer simplesmente que ele é uma representação do passado - ele representa uma viagem no tempo, que permite ao visitante inúmeras sensações físicas e emocionais através de vários equipamentos que remontam a seu passado e que dão sentido à origem de seus costumes e a história da sua vida, família, cidade ou mesmo do seu país (FUNARI, 2005). 
Entretanto, além de toda essa carga histórica e cultural, existem outros fatores que motivam a visitação de um patrimônio, dentre elas, a curiosidade, que é uma das características humanas, seja por um fato que ocorreu no lugar, ou mesmo, apenas que se ouviu falar; tais fatores ganham mais sentido com a presença do indivíduo que permite novas experiências de grande relevância e que são motivados ou pelos desejos pessoais do turista ou simplesmente pelo status social adquirido no simples fato de relatar a sua passagem pelo local de prestígio.

É preciso considerar que um patrimônio comercializado através do turismo deva possuir, de antemão, uma relação de identidade e de memória consolidada com a população local, observando se os autóctones o consideram como um bem que deve ser respeitado e preservado, para que, em um segundo momento possa "dividi-lo" com os visitantes, através das práticas do Turismo Cultural.

Partindo desse pensamento, de que a população local é parte importante para a valorização de um patrimônio, assim como uma das responsáveis pela sua preservação, tem-se como uma das formas mais comuns de preservação o tombamento com todos os seus critérios e diretrizes.

O presente trabalho tem como tema o patrimônio histórico, sua relação com o turismo e com a população local, de forma a discutir o aparente descaso em relação à situação atual do centro histórico de Parnaíba.

Além disso, teve como objetivo geral a análise da sensibilização e do reconhecimento cultural da população parnaibana em relação à importância histórica e turística do Porto das Barcas, tendo como objetivos específicos caracterizar o nível de conhecimento histórico da população em relação ao Porto das Barcas, verificar a causa do abandono do complexo e analisar a potencialidade turística do Porto das Barcas.

\section{O Patrimônio "Porto das Barcas"}


O Porto das Barcas (Parnaíba/PI) é composto por armazéns construídos em meados do Séc. XVIII, sendo que, atualmente, alguns se encontram em ruínas e abandonados e outros servem como ponto comercial para lojas de artesanato e agências de viagens. Através do tempo as edificações foram perdendo parte de sua arquitetura original, devido à idade da construção e ao mal cuidado, tanto dos responsáveis pelo local como pela população em geral. Ações estas detectadas pelos visitantes e em reportagens de circulação local.

Então, dentro de um contexto em que a transformação de um local em um patrimônio parte inicialmente da sensibilização da população local, questionou-se então se a população parnaibana se sensibiliza e reconhece o Porto das Barcas como um patrimônio histórico potencialmente turístico.

O patrimônio histórico e arquitetônico no Brasil parece ainda não atender satisfatoriamente ao desenvolvimento da indústria turística, a não ser em casos isolados e já consagrados, como o das cidades históricas, em especial as mineiras, embora, nos últimos anos, muitos bens culturais brasileiros tenham sido considerados "patrimônio da humanidade", categoria de reconhecimento internacional criada pela UNESCO, em 1972, que, pela própria divulgação que propicia, favorece o aproveitamento turístico.

Todo homem tem direito ao respeito aos testemunhos autênticos que expressam sua identidade cultural no conjunto da grande família humana; tem direito a conhecer seu patrimônio e o dos outros; tem direito a uma boa utilização do patrimônio; tem direito de participar das decisões que afetam o patrimônio e os valores culturais nele representados; e tem direito de se associar para a defesa e pela valorização do patrimônio.

Com base nessas condições o presente trabalho se faz importante, pois, de uma forma isolada, tentará identificar as causas dos problemas encontrados e expostos na parte de problematização da pesquisa e a viabilização de uma mudança, ainda que modesta, no quadro em que se encontra o complexo, podendo assim iniciar um trabalho em que a sensibilização da população já se torne um fato, e não mais uma utopia, adquirindo com isso uma reafirmação da identidade local, de forma a deixá-la mais concreta no consciente da 
comunidade, fazendo com que esta se sensibilize e comece a interagir com o seu patrimônio.

Outro tópico importante é o de oferecer ao turista outras opções de lazer, para que quando o mesmo chegue à cidade possa usufruir de todos os direitos que the assiste em relação à possibilidade de conhecimento da cultura do outro. Sem falar no fato de que Parnaíba vive basicamente da promoção e venda de passeios ao Delta, isso falando num olhar mais turístico, e demonstrar como a prática de um turismo voltado para a cultura pode demonstrar um segmento promissor para a atividade na região.

O trabalho em questão parte de uma visão generalizada do turismo, ressaltando o turismo cultural, pois se considera de suma importância a conceituação do mesmo para que possa se entender como funciona a construção da relação entre turismo e patrimônio.

\section{Metodologia Utilizada}

O tipo de pesquisa utilizada foi um estudo de caso, pois se pretende estudar um fenômeno específico, que envolve a cidade de Parnaíba e o complexo Porto das Barcas. Como também a pesquisa de caráter quantiqualitativa, pois envolve a observação intensiva, o registro preciso e detalhado do que acontece no ambiente e a interpretação e a análise dos dados utilizando descrições e narrativas.

Entrevistas com os grupos de atores sociais considerados os principais responsáveis pelo incentivo do turismo na cidade e pela promoção dos atrativos da região também se fazem presentes.

Visitas ao local, na parte da manhã, para as entrevistas com agências de viagens e comerciantes e à noite para observação do movimento de pessoas, também são contempladas.

Do mesmo modo, entrevistas com aplicação de questionários com perguntas abertas e fechadas e de caráter não-diretivas e a observação do movimento no local são consideradas importantes neste trabalho. 
Faz-se presente também uma entrevista informal com a representante do IPHAN, Andréa Cruz, sobre os planos de revitalização do Porto das Barcas.

Com relação à amostragem foram escolhidos como público-alvo três grupos de agentes, que podemos considerar responsáveis pelo incentivo e pela implantação da atividade turística da região, são eles: as secretarias de turismo e cultura do município (representando o poder público); as agências de viagens receptivas do entorno e os comerciantes instalados no Porto das Barcas (representando o poder privado); e a população local, com o universo de amostra de 60 pessoas, pois foi este número da quantidade de pessoas que freqüentou a região do porto das Barcas nos dias da pesquisa.

A justificativa pela escolha dos públicos para as entrevistas se dá pelo fato de que as secretarias são responsáveis no que diz respeito:

- à elaboração e implantação de políticas públicas condizentes com a situação do local exposto;

- à elaboração e implantação, por parte das agências de viagem, mas agora de roteiros que envolvam o cenário urbano da cidade, principalmente o Porto das Barcas;

- aos comerciantes, que instalaram suas lojas de artesanato no local. É importante destacar que, com a escolha do Porto das Barcas como ponto de venda, pretende-se obter os critérios utilizados para tal instalação;

- à população do entorno, dando-se preferência a esse grupo especificamente, por ser um público que convive diariamente com a situação do centro histórico e por ser uma testemunha ocular diária de tudo que acontece no local.

Os questionários, por sua vez, apresentam perguntas distintas em número e conteúdo, preocupando-se sempre com as possibilidades de relações entre as perguntas havendo um cruzamento nas respostas dos entrevistados.

A coleta de dados ocorreu no período de abril a maio de 2010, disposta na seguinte ordem:

a. Entrevistas com as agências de viagens receptivas

b. Entrevistas com os representantes da Secretaria Municipal de Turismo 
c. Entrevistas com alguns comerciantes e com parte da população do entorno.

Após as entrevistas e a aplicação de questionário optou-se por aplicar a análise SWOT que, de acordo com Dornelas (2005 apud Perinotto, 2006), atualmente a análise ambiental baseada na SWOT é um fator fundamental na elaboração de um plano de marketing turístico que dê um retorno esperado para a cidade. Uma vez identificadas as principais oportunidades e ameaças enfrentadas pela localidade, é possível caracterizar sua atratividade global.

Através do planejamento estratégico a empresa ou organização espera (OLIVEIRA, s/d apud PERINOTTO, 2006):

a) Conhecer e melhor utilizar seus pontos fortes. Ponto forte é a diferenciação conseguida pela empresa que Ihe proporciona uma vantagem operacional no ambiente empresarial (variável controlável)

b) Conhecer e eliminar ou adequar seus pontos fracos. Ponto fraco é uma situação inadequada da empresa que lhe proporciona uma desvantagem operacional no ambiente empresarial (variável controlável).

c) Conhecer e usufruir das oportunidades externas e internas. Oportunidade é a força ambiental incontrolável pela empresa, que pode favorecer a sua ação estratégica, desde que conhecida e aproveitada satisfatoriamente enquanto perdurar.

d) Conhecer e evitar as ameaças/riscos externos e internos. Ameaças/riscos são as forças ambientais incontroláveis pela empresa, que criam obstáculos à sua ação estratégica, mas que poderão ou não serem evitadas desde que conhecidas em tempo hábil.

\section{Revisão da Literatura e Discussão}

Turismo e Turismo Cultural

A atividade turística pretende ganhar espaço na economia brasileira podendo ser considerado um dos carros chefes na arrecadação de receita do país. Partindo da idéia de que todos, de alguma forma, já viajaram ou 
ISSN: $1982-6125$

pretendem viajar algum dia, é que o turismo se torna cada vez mais consistente no Brasil.

O hábito de viajar é antigo. No séc. XVII, as boas famílias mandavam seus filhos completarem a educação com viagens nas quais aprendiam línguas costumes de outros povos, compravam obras de arte e visitavam os monumentos da Antiguidade, como o Fórum em Roma (FUNARI e PINSKY, 2005, p.15).

Porém, assim como sua complexidade, o Turismo assume outras várias definições que constituem a mesma essência, o deslocamento. Tribe (s/d apud Köhler e Durand, 2007) oferece definição ampla, que captura a complexa e multifacetada natureza da atividade: "[Turismo é] o conjunto dos fenômenos e das relações que emergem da interação em regiões emissoras e receptivas, de turistas, empresas fornecedoras, órgãos de governo, comunidades e ambientes", ou seja, envolve setores que participam da gestão de uma localidade, fazendo com que estes se relacionem e trabalhem em harmonia no desempenho da atividade.

O turismo consiste no movimento de pessoas para destinos fora de seus ambientes normais de trabalho e residência, para o desenvolvimento de atividades que contrastam com as ações empreendidas em seu dia a dia. Isso caracteriza a atividade turística como um período de exceção, presidido pela intenção, por parte do viajante, de retornar a seu ambiente de origem após um determinado período de tempo, geralmente curto.

De acordo com Beeho e Prentice (s/d apud Köhler e Durand, 2007), o produto turístico baseia-se essencialmente em experiências intangíveis, a partir dos benefícios, fantasias e interpretações que as atrações possibilitam ao turista. As experiências não são algo universal ou padronizado, mas sim vividas e interpretadas diferentemente por cada turista, a partir de seus sentimentos, visão de mundo, repertório cultural e pré-concepções.

Então, de forma a fundamentar ainda mais esse conceito, é necessário colocar aqui o conceito de turismo cultural, pois, partindo da idéia de que a motivação é o que impulsiona o deslocamento de pessoas, coloca-se o turismo 
cultural como uma atividade impulsionada pelo desejo de se conhecer a cultura do outro.

No entanto, antes deve-se fazer um breve comentário sobre cultura, assim como sobre sua relação com o turismo, para podermos definir e entender esse segmento.

De acordo com Gomes (2007):

A cultura seria um emaranhado de teias de significados e as conseqüentes análises, que são construídas ao longo do tempo por seus componentes, compreendendo-a através de seu aspecto semiótico, que se constitui como uma ação simbólica repleta de significados.

Deste modo, podemos dizer que a cultura parte não só dos conjuntos de significados, mas de como a sociedade os interpreta e, por conseguinte, agrega-lhes valor.

Também pode-se dizer que cultura é o conjunto de instrumentos de que dispõe a mediação simbólica (línguas, leis, ciências, artes e mitos) para permitir ao indivíduo a abordagem do real. Instrumentos estes que são usados coletivamente, colocados à disposição de todos.

De acordo com Bennett (s/d apud Köhler e Durand 2007), o termo cultura pode ser usado para designar um produto ou processo, que serão explicados a seguir. No primeiro caso (produto), cultura significa o resultado do conjunto de atividades artísticas e culturais, na forma de produtos tangíveis ou não. Nele, a cultura consiste em edifícios, músicas, danças, pinturas, festivais, entre outros produtos. No segundo caso (processo), cultura assume amplitude antropológica, referindo-se ao modo de vida de uma determinada população.

O turismo possui reconhecidamente força enquanto fenômeno social e econômico capaz de gerar impactos de diferentes magnitudes.

A intensidade desses impactos costuma ser dividida em áreas nas quais o turismo tem influência: na economia local, regional, nacional ou mesmo internacional; no meio ambiente, seja ele natural ou artificial; e na esfera sociocultural, o que abrange fatores comportamentais dos turistas e da 
comunidade receptora e as inter-relações do turismo com as diversas tradições e culturas das regiões visitadas.

Assim, a atividade turística produz inúmeras conseqüências nas comunidades, podendo ser divididas em aspectos positivos e negativos (GOMES, 2007).

Quanto aos aspectos positivos tem-se: a valorização do artesanato local, da herança cultural, orgulho étnico, valorização e preservação do patrimônio histórico-cultural, intercâmbio cultural, troca de valores, vivência emocional e espacial, melhoria em infra-estrutura pública e geração de empregos e renda.

Já no grupo dos aspectos negativos se encontram a super utilização de sítios e localidades, a falta de controle local sobre a dinâmica da atividade, (a deficiência nos controles de capacidade de carga de cada cidade), a trivialização ou perde-se a autenticidade, drogas, prostituição, especulação imobiliária, descaracterização do artesanato e arquitetura, vulgarização das manifestações culturais, autenticidade encenada, mercantilização, mudança nos costumes e valores, crimes, enfim, uma série de coisas comuns a cidades saturadas pelo turismo (SWARBROOKE, s/d apud GOMES, 2007).

Deve-se levar em consideração que todo esse processo negativo citado anteriormente não é totalmente causado pelo turismo em si, mas sim acelerado por ele. Portanto, não se deve culpar o turismo por tais impactos, pois a comunidade passa por diversas mudanças sociais que afetam as sociedades atuais no processo de modernização, ou seja, as comunidades sempre vão sofrer mudanças, independente da ação da atividade turística.

Essa atividade que une o turismo e a cultura denomina-se de turismo cultural, definido de maneira estreita como aquele segmento que trata das viagens de estudo, um item importante na pauta de alguns países, especialmente de língua inglesa, como a Grã-Bretanha e os Estados Unidos (FUNARI e PINSKY, 2005 p.7). Contudo, a cultura não se limita ao estudo formal, ao contrário: todas as ações fazem parte da cultura.

De uma forma geral, ao visitar um lugar onde o motivo da viagem é unicamente o estudo é inevitável a interação entre os atores participantes, o 
que pode ser denominado como intercâmbio cultural, em outras palavras, essa interação é uma ação própria do turismo, e como afirmado acima, toda ação é cultural, então entende-se que toda forma de turismo se caracteriza como um turismo cultural.

A busca por uma representação do passado se tornou uma necessidade atualmente. Tem-se a necessidade de vivenciar o passado em forma de eventos relacionados, através dos inúmeros símbolos, que trazem consigo um conjunto de significados de forma a deixar mais perto do indivíduo contemporâneo a forma de vida dos seus antepassados.

Partindo da idéia de que não é o que se vê, mas como se vê, que melhor caracteriza o turismo cultural (FUNARI e PINSKY, 2005), dá-se um exemplo de um grupo que se propõe a visitar a Europa em apenas duas semanas, onde todos dentro do ônibus falam a mesma língua.

Nessas viagens as paisagens são vistas apenas através dos vidros, sem nenhum outro tipo de contato. Nas rápidas paradas, as pessoas são avisadas de que há um determinado artefato importante para a história, e que seria interessante que tirassem fotos do mesmo, porém em nenhum momento o grupo sai do ônibus para obter um contato mais próximo com o bem patrimonial da cidade. Será esse um turismo cultural?

Então, pode-se discutir o fato de que o deslocamento por si só já se constitui um fato cultural. Talvez fosse mais adequado dizer que o turismo cultural se concretiza quando há a apropriação de algo que possa ser caracterizado como bem cultural. Porém, essa apropriação pode ser feita através da interação com a população local de forma mais simplificada, para que possa tornar a experiência da viagem satisfatória, daí a importância do engajamento da comunidade no planejamento do turismo da região.

O que é patrimônio histórico?

Assim como as definições relacionadas ao turismo, o conceito de patrimônio também é discutido e assume sentidos diversos. A discussão acerca 
do conceito de patrimônio histórico partiu essencialmente da Europa, principalmente por conta de ser considerada (Europa) uma das civilizações mais antigas, ou seja, possuindo muita história pra contar.

No séc. XVIII, quando na França, o poder público começou a tomar as primeiras medidas de proteção aos monumentos de valor para a história para as nações, o uso de "patrimônio" estendeu-se para os bens protegidos por lei e pela ação de órgãos especialmente constituídos, nomeando, o conjunto de bens culturais de uma nação (FUNARI e PINSKY, 2005, p.16).

A criação dos patrimônios nacionais serviu para instituir referências comuns a todos que habitavam o mesmo território, unificá-los em torno de pretensos interesses e tradições comuns, gerando a imposição de uma língua nacional, de costumes nacionais, de uma história nacional, que se sobrepõe às memórias particulares e regionais.

Então, no século XIX, o patrimônio passou a ser considerado um conjunto de símbolos unificados, ilustrando a história de uma sociedade para que os habitantes desta se identificassem com a história dos seus antepassados, embora existissem distintos grupos sociais e étnicos presentes no mesmo território, transformando, assim, o patrimônio em uma construção social de extrema importância política.

Na Convenção do Patrimônio Mundial da UNESCO (United Nations Educational, Scientific and Cultural Organization), em 1972, o patrimônio cultural, até o momento chamado de patrimônio histórico, passou a ser considerado como "o conjunto de edificações separadas ou conectadas, os quais, por sua arquitetura, homogeneidade ou localização na paisagem, sejam de relevância universal do ponto de vista da história, da arte ou das ciências" (BARBOSA s/d apud GOMES, 2008).

Pode-se dizer, então, que este conceito acima restringe o patrimônio cultural a construções como casarões, palácios, entre outros, que possuem um significado histórico não somente nacional, ou seja, de valor simbólico para um determinado país, mas universal ligando a todos do planeta. Dá-se como 
exemplo as descobertas históricas a cerca da evolução humana, as pinturas de artistas mundialmente conhecidos como Leonardo da Vinci e no campo da ciência tem-se a descoberta da cura de epidemias, de circulação mundial.

No entanto, Pellegrini (s/d apud Gomes, 2008) ressalta que o significado dos patrimônios culturais é muito amplo, sendo incluídos outros produtos do sentir, do pensar e do agir humanos, variadas peças de valor etnológico, arquivos e coleções bibliográficas, desenhos de sentido artístico ou científico, peças significativas para o estudo da arqueologia de um povo ou de uma época, e assim por diante; tudo somado no que se pode denominar o meio ambiente artificial.

Sendo esse o que podemos chamar de ambiente construído por uma sociedade, pois a idéia de artificial se refere a algo produzido pela arte ou pela indústria.

Contudo, patrimônio histórico e patrimônio cultural assumem definições distintas, mas continuam permanecendo na mesma essência. Sendo patrimônio histórico os bens de caráter tangível (edificações, documentos, objetos, etc.) e o patrimônio cultural abrange tanto os bens tangíveis como as manifestações populares, a forma de falar, a culinária, ou seja, os de caráter intangível.

Impossível falar de patrimônio histórico sem falar de memória, pois, de uma maneira geral, o patrimônio serve como uma ponte entre o passado e o presente, na intenção de manter viva a memória de um lugar. Então a memória colocada aqui pode ser denominada memória social, pois está relacionada à memória de uma sociedade junto aos eventos cívicos que marcaram sua construção.

Baseado nisso, a construção do patrimônio se dá através da importância que este tem para a história, contada através do tempo. Para Funari e Pinsky (2005) o patrimônio, como parte integrante da memória social, se destaca como um campo de conflito simbólico, como um jogo memória/esquecimento, sujeito a imposição do poder dominante que declararia como verdade a sua 
memória. Na verdade, a construção do patrimônio depende da importância que um indivíduo, ou um grupo de indivíduos, dá a um determinado objeto.

Cabe aqui falar sobre a importância da valorização da sociedade com o seu patrimônio, a importância que esta atribui ao mesmo.

O cuidado, por parte desses atores sociais, com o patrimônio é de suma importância na caracterização da identidade da cidade de forma a diferenciá-la das outras, então:

Uma população sem patrimônio é um conjunto de pessoas sem história, sem cultura, sem tradição. Determinado bem cultural não precisa necessariamente possuir atratividade turística, mas o cuidado e o interesse por parte dos residentes não deve deixar de existir (GOMES, 2007, p.2).

A questão não fica restrita somente a sua valorização, mas também a sua promoção e conversação frente ao turismo. As formas de uso do patrimônio devem estar voltadas para a satisfação da população. Como afirma Reis (s/d):

O uso adequado do patrimônio tem que exercer duas funções: garantir o respeito à cultura, inclusive no que se refere aos estilos artísticos, garantir o significado histórico e o respeito à comunidade, que não pode ser excluída do processo de decisão sobre o assunto do patrimônio ou mesmo dos benefícios econômicos advindos da atividade turística.

Como o objeto de pesquisa desse artigo se refere ao Porto das Barcas, faz-se necessário relembrar um pouco de sua história, de modo a justificar a importância deste bem para a cidade de Parnaíba.

\section{Breve História do Porto das Barcas}

O complexo cultural Porto das Barcas, que se caracteriza como um patrimônio histórico da cidade de Parnaíba - PI, situado no centro da cidade, ilustra, através de suas ruínas, fatos da história que se misturam com momentos de apogeu e decadência da região. 
A história do Porto se confunde com o apogeu econômico da cidade de Parnaíba, principalmente nos períodos da cera de carnaúba, do couro e da carne de charque, produtos de grande valor econômicos da época.

Inicialmente o Porto das Barcas era chamado de Porto Salgado e servia como ponto de armazenamento de mercadorias prestes a serem exportadas e importadas.

Sua arquitetura possui várias influências por conta da imigração dos estrangeiros da cidade. Atualmente é constituído por galpões, alguns funcionando como pontos comerciais para agências de viagens e lojas de artesanato e souvenir, outros estão abandonados, sujeitos a ação do tempo e degradação do homem.

\section{O Porto das Barcas e o Turismo}

A construção de um patrimônio é concretizada a partir da valorização da população local. Porém, para que haja a valorização é necessário que a comunidade reconheça o valor do bem histórico, se identifique com ele, ou seja, é necessária a existência de ações de sensibilização, para que esta possa identificar a importância não só histórica como também cultural de determinado bem da cidade, podendo, assim, viabilizá-lo para o turismo.

Portanto, as ações de sensibilização são ferramentas usadas para atingir a população no tocante à relevância de um determinado patrimônio.

Em outras palavras, a sensibilização para o turismo se dá pelo esforço de se ouvir primeiramente a comunidade.

Sabe-se que a sensibilização é uma peça importante para a viabilização de algo para o turismo, de forma a mostrar que essa atividade, se praticada adequadamente, pode se tornar um importante gerador de emprego e renda para a população do local.

A relação entre o patrimônio histórico e o turismo pode não ser muito harmônica, porém com planejamento e a participação popular pode vir a ser uma relação bem promissora. 
Pode-se dizer que o universo material e simbólico da produção cultural do espaço se tornou objeto do olhar turístico, fenômeno que valoriza os bens de diferentes expressões culturais, fortalecendo a atratividade dos lugares. Identidades territoriais, muitas vezes esquecidas pelos próprios grupamentos culturais aos quais pertencem, emergem como objetos de consumo valorizados na mercantilização turística das paisagens, dos lugares e dos territórios e ganham novas dimensões econômicas, políticas e também culturais (BARTHOLO, SANSOLO, BURSZTYN, s/d).

Então, baseado na afirmação acima, o turismo atua como uma ação de valorização da cultura, principalmente quando essa atividade é vista pela população como geradora de emprego e renda. Toma-se como exemplo a instalação de lojas de souvenir no entorno e até mesmo no próprio patrimônio, como é o caso de lojas de artesanato e souvenir dentro do Centro Histórico de São Luís, como também do Porto das Barcas.

Porém, para cada grupo social existe uma forma social, uma pauta religiosa, uma condição de linguagens simbólicas que permitiram transformar, gradativamente, o espaço em um acúmulo de formas muito características, que, hoje, contracenam com o mundo pós-moderno, em uma relação não muito harmônica, porém com possibilidades de geração de renda e emprego, com a prática de atividades diversas, dentre elas o turismo (PORTUGUEZ, 2004).

Então, cada região possui uma singularidade cultural, uma característica capaz de atrair visitantes, motivados seja pela curiosidade sobre o local seja pelo status originado pela visitação de uma determinada localidade. No entanto, essas motivações são características que impulsionam a atividade turística, sustentada por equipamentos e serviços que apóiem a realização dessa atividade.

Durante esta pesquisa foram realizadas entrevistas com os atores sociais, considerados tanto como os responsáveis pelo planejamento como os principais beneficiados com a atividade turística realizada no município.

Os atores citados são: 
- Os representantes de agências de viagens;

- A SETUR municipal;

- População local.

Conforme coletado durante a pesquisa, pôde-se perceber um distanciamento entre esses três poderes, sendo este problema inicialmente evidenciado pelo fato de que os funcionários das agências relatarem que o principal produto vendido por Parnaíba é o Delta, fato que entra em desacordo com as respostas obtidas com o representante da SETUR municipal, que relatam como principal produto vendido a Praia Pedra do Sal, praia legítima de Parnaíba.

Em relação aos comerciantes do entorno, o que se destaca para essa pesquisa é a opinião dos turistas que visitam o porto. Segundo os turistas o que mais falta no local é limpeza e maior uso da população do local, ou seja, o Porto das Barcas encontra-se em muitos aspectos sujo e degradado, assim como sua população não a visita, fato que, se ocorresse ao contrário, caracterizaria uma valorização por parte desta. Lembrando que esse relato está relacionado às considerações dos turistas sobre o local.

Quanto à população, o que se pode observar é que existe um certo distanciamento desta com a realidade do porto, principalmente na viabilização do mesmo para o turismo. Dentre algumas questões deve-se fazer comentário sobre quando se pretende identificar da população o conhecimento sobre o turismo, $15 \%$ dos entrevistados não sabem o que é turismo ou não souberam defini-lo, porém, essa porcentagem está equilibrada com aqueles que considerem o turismo como uma atividade geradora de emprego e renda. Isso implica em dizer que a atividade turística não é muito familiar para a população parnaibana.

Ainda falando sobre a população, no quesito conhecimento sobre a história da própria cidade, assim como do Porto das Barcas, a maioria dos entrevistados relatou conhecer muito pouco ou nada, fato que justifica o distanciamento da população com a preservação do local, pois, como pode uma sociedade preservar um bem se não reconhece sua importância histórica 
e cultural para a mesma? E ainda tem-se que relatar que não existe uma freqüência de visitação ao local praticada pelos habitantes em seus momentos de folga, apesar de os mesmos considerarem o Porto potencialmente turístico.

\section{Descrição e Breve Análise dos Dados}

Conforme citado na metodologia, além da pesquisa bibliográfica sobre o assunto, houve também a busca por informações mais específicas do Porto das Barcas em órgãos públicos de pesquisa do município, com poucos resultados específicos. Existe material escrito sobre o Porto das Barcas, mas em um contexto mais histórico, falando de sua história e como se confunde com o desenvolvimento de Parnaíba.

Em relação à entrevista com a representante do IPHAN realizada no mês de abril - lembrando que esta não se encontra na cidade, passa apenas de quinze em quinze dias - a Dr. Andréa Cruz, arquiteta encarregada do IPHAN para a cidade de Parnaíba, falou que não participou do processo de tombamento do centro histórico e não dispõem de informações sobre o assunto, pois a mesma está no cargo há pouco tempo e não está a par desse assunto, mas afirma existir alguns projetos de revitalização voltados para 0 Porto. Quando pergunto sobre a participação popular a mesma responde dizendo que existe a participação da população, mas como não se pode atingir a todos são escolhidos os formadores de opiniões e os mesmos participam da explanação do projeto.

De forma a nos aprofundarmos no assunto deste trabalho é necessário discutirmos esse fato, que por sua vez se caracteriza como uma deficiência no que diz respeito ao envolvimento da população parnaibana na valorização do seu patrimônio. Durante todo o trabalho é mostrada a importância da comunidade nas decisões quanto à utilização do patrimônio da mesma, sabese que não é uma tarefa fácil mobilizar toda uma comunidade, se é que isso é possível, pois nem todos os habitantes são simpatizantes da idéia, principalmente quando envolve assuntos morais ou econômicos. 
Por isso tem-se a necessidade de incluir ações de sensibilização com todas as diretrizes bem definidas para que se possa alcançar o resultado desejado e de preferência atingindo boa parte da população local.

Entrevistas com as agências de viagens: nas entrevistas nãodiretivas realizadas com as agências de viagens, em meados de maio "seis ao todo", precisa ser destacado que não se pôde fazer a entrevistas com todas as agências, pois duas delas estavam fechadas, totalizando-se, então, 4 entrevistas, de onde extraíram-se os seguintes resultados:

a. Todas as empresas possuem tempo de vida de mais de 10 anos.

b. Quando pergunto sobre o principal produto vendido na empresa, por unanimidade respondem o Delta e a Rota das Emoções.

c. Em relação a um pacote vendido dentro da cidade como um city tour, apenas uma respondeu que existe um roteiro já estabelecido, mas que depende, é claro, da vontade do cliente; as outras responderam que fazem apenas quando Ihes é solicitado e todas admitem que não é freqüente esse pedido.

d. Quando se pergunta sobre o controle da demanda nenhuma possui uma pesquisa estruturada e realizam apenas de forma bem informal na alta temporada.

e. Em relação à opinião dos empresários das agências sobre o que falta para que o Porto das Barcas tenha mais atratividade, apenas um citou a participação popular na utilização da área de lazer do Porto, e em sua maioria citaram que deveria haver mais eventos e entretenimento para chamar os turistas.

\section{Entrevista com o representante da Secretaria de Turismo} Municipal (SETUR): a secretaria funciona há mais ou menos um ano, pois antes era vinculada a outras secretarias, então houve um desmembramento que dividiu as secretarias vigorando, desde então, o formato que se conhece hoje. A entrevista foi realizada no mesmo período que as das agências.

Quando questionado sobre a existência de alguma pesquisa de demanda, a SETUR informa que não dispõe de uma pesquisa de demanda do perfil do 
ISSN: $1982-6125$

turista que vem à cidade, porém diz estar com uma em andamento onde são usadas, na condição de pesquisadores, alunos da UFPI, o que encontra-se ainda em fase de conclusão.

Sobre o principal produto vendido pela cidade, aos olhos da SETUR, é a Pedra do Sal, praia legítima de Parnaíba, e quando questiona-se sobre o Delta a mesma o inclui, mas ressaltando a importância da praia. Verifica-se com isso uma incoerência nas respostas e certo distanciamento do representante do poder público em relação à situação atual do município.

Sobre os projetos de autoria da secretaria a mesma cita apenas projetos voltados para eventos, mas ressalta que existem projetos já encaminhados para a revitalização do Porto das Barcas, assim como o da Beira Rio. No entanto esses projetos são da SETUR estadual e contam com o apoio da prefeitura de Parnaíba.

Sobre a participação popular, o representante da secretaria, em entrevista, disse que já houve várias reuniões, onde foram mostradas as plantas e todo o projeto para a revitalização dos lugares, e que, segundo o representante da secretaria, na reunião ficava aberto aos ouvintes qualquer tipo de manifestação. Mas o projeto ainda não se encontra disponível em redes de comunicação local.

Entrevistas com os comerciantes: durante os dias da pesquisa foram encontradas apenas duas lojas de artesanato e souvenir abertas no Porto das Barcas.

Entrevistas com a população: durante dois dias foram aplicados os questionários com a população parnaibana, de forma aleatória os questionários foram aplicados com as pessoas que por lá andavam.

A primeira etapa foi realiza na parte da manhã e a segunda e última parte realizada pela tarde. Como já foi citado na metodologia, a amostragem da pesquisa foi de 60 pessoas, por esgotamento, pois foram as pessoas que freqüentaram a localidade nos horários de aplicação dos questionários.

\section{Considerações Finais}


A cidade de Parnaíba é de suma importância para o Piauí, pois fez parte da construção e desenvolvimento do Estado. Para tanto, essa cidade tem um acervo histórico igualmente importante, que como se vê na pesquisa, não é valorizado.

O Porto das Barcas pode ser considerado como um dos principais bens históricos de Parnaíba, porém, sofre um doloroso processo de abandono. Como se pôde observar, os atores sociais, responsáveis pela proteção e promoção do patrimônio, não trabalham em harmonia, adotando com isso uma postura alheia às reais necessidades da cidade.

Não se pode visar o bem do todo, trabalhando cada um por si, sem o envolvimento da comunidade, porém, esse envolvimento tem que ser atuante e participativo para que se possa chegar ao desenvolvimento do local.

De forma a responder ao objetivo geral deste trabalho, deve-se destacar que a população parnaibana não interage com o Porto das Barcas, no sentido de que ela não se sensibiliza em relação à importância histórica e cultural do bem para a cidade, ou seja, ao mesmo tempo em que ela o reconhece como potencialmente turístico enquanto patrimônio histórico, não participa da construção do planejamento para a atividade no local. No entanto, isso se caracteriza como uma postura passiva, porém o poder público, assim como o poder privado, possui sua parcela de culpa nesse fenômeno.

De fato, esses poderes não incentivam a participação popular, concentrando as informações sobre os projetos de revitalização somente para eles. Isso gera acomodação e faz com que a população não se sinta dona do patrimônio, ou seja, ao invés de se mobilizarem e começarem a cobrar mais investimento para o Porto, esta se recolhe, mantendo-se distante do planejamento dessa localidade.

No entanto, isso pode ser explicado por conta de que população não conhece muito da história local, um exemplo: poucos sabem que o Porto das Barcas foi importante para a cidade de Parnaíba, desses alguns poucos não sabem em que circunstâncias originaram-se essa importância. 
Como causa do abandono de parte do bem patrimonial, pode ser pela falta de uma ação de tombamento municipal, pois isso pode ilustrar o desapego do município em relação ao Porto das Barcas. Uma vez que se não houve valorização de cunho público, o setor privado toma conta e pode fazer com a localidade tenha possibilidade de perder suas características históricas.

Outro fator que pode se destacar como causador do abandono do lugar é a falta de atratividade para a população, ou seja, o Porto não possui incentivos que visem à atração tanto dos turistas, como também da população local, sendo esta última a que deve ser a principal beneficiada com esses incentivos, na localidade, existe a proximidade com o centro comercial, com a ponte que leva à Ilha Grande (porta de entrada do Delta do Parnaíba), ou seja, o Porto da Barcas está em um ponto estratégico de potencial atração de lazer e por conseguinte de Turismo.

Sobre a potencialidade do mesmo é preciso haver, antes de tudo, a reparação dos problemas expostos acima, como a falta de interesse do poder público e privado, assim como a falta de interação desses com a comunidade, a inexistência do tombamento municipal, de forma a visar o bem estar de todos, para que possam, posteriormente, pensar em um planejamento para o turismo. De fato o Porto das Barcas possui potencial turístico e pode vir a se tornar um grande ponto turístico da cidade.

Como propostas têm-se, de início, a concretização do tombamento municipal, para que se possa reforçar a importância do Porto para a cidade, implantação de uma educação patrimonial nas escolas da cidade, de forma a começar desde cedo a conscientização para o valor de um patrimônio para, depois disso, pensá-lo como um bem turístico.

Ações de sensibilização da comunidade, incentivos à cultura, assim como eventos e entretenimento para os visitantes e população local, também são propostas adequadas consideradas pela pesquisa.

Por último, e não menos importante, a criação de um museu fotográfico, com ilustrações de momentos antigos do Porto das Barcas, mostrando a sua história, para que fique de forma mais fácil aprendê-la. No entanto, como foi 
ISSN: $1982-6125$

discutido até agora, esse museu deve ser construído pela população, ou seja, cada um terá que contribuir com essa criação, com opiniões, sugestões, acervos pessoais, enfim, fazer de uma forma que todo parnaibano se sinta dono do museu, fazendo parte da construção do mesmo.

O Porto das Barcas como um bem importante da cidade faz parte do cotidiano dos parnaibanos, só falta estes se sensibilizarem e então visualizarem-no como tal.

\section{Referências}

BARTHOLO, Roberto; SANSOLO, Davis Gruber; BURTSZTYN, Ivan. Turismo de base comunitária : diversidades de olhares e experiências brasileiras. (Orgs.) MTUR, S/D.

FUNARI, Pedro Paulo; PINSKY, Jaime. (Org.) Turismo e patrimônio cultural. 4.ed. São Paulo: Contexto, 2005. 130p.

GOMES, Mariana Elias. Patrimônio Cultural e Turismo: um estudo de caso sobre a relação entre o órgão Arp Schinitger e a população local de Mariana, MG . 2007

IPHAN. Conjunto histórico e paisagístico de Parnaíba. 2008. 40p.

LEMOS, Carlos A. C.. O que é Patrimônio Histórico? São Paulo: Brasiliense, 2006, 51p. Coleção Primeiros Passos.

LOSEKANN, Silvana. Porto das barcas continua sendo roubado e depredado. Disponível em: www.defender.org.br

MINISTÉRIO DO TURISMO. Plano Nacional de Turismo 2007 - 2010: uma viagem de inclusão. Brasília, Mtur, 2007.

KOLHER, André Fontan; DURAND, José Carlos Garcia. Turismo cultural: conceituação, fontes de crescimento e tendências. Turismo Visão e Ação, vol.9 n.2, maio/agosto 2007.

MENDES, Francisco Iweltman Vasconcelos. Parnaíba: Educação e Sociedade. SIEART, 2007. 121p.

PERINOTTO, André Riani Costa. Estratégias de desenvolvimento turístico em municípios pequenos segundo uma perspectiva regional: o caso de Analândia SP. Dissertação de Mestrado. UNESP/Rio Claro-SP. 2006.

PORTUGUEZ, Anderson Pereira. (Org.) Turismo, memória e patrimônio cultural. São Paulo: Rocca 2004. 204p.

PIRES, Fabiana Mendonça. Percepções sobre o patrimônio edificado em Tiradentes - MG. Revista Eletrônica de Turismo Cultural. Segundo semestre, 2007.

REIS, Fábio José Garcia dos. Patrimônio cultural: revitalização e utilização. S/D. 
ISSN: $1982-6125$

SESC. Diretrizes de ação do SESC - Turismo Social. Disponível em <www.sesc.com.br>. Acesso em: 31 de junho de 2010.

SILVA, Elsa Peralta da. Patrimônio e identidade: os desafios do turismo cultural. Universidade Técnica de Lisboa, S/D.

SOUZA, Rafael Pereira de. Turismo, patrimônio histórico/cultural e identidade. UNISUAM, 2009.

Artigo recebido em março de 2011.

Aprovado para publicação em julho de 2011. 